\title{
Spinocerebellar ataxia type 2
}

INSERM

\section{Source}

INSERM. (1999). Orphanet: an online rare disease and orphan drug data base.

Spinocerebellar ataxia type 2. ORPHA:98756

Spinocerebellar ataxia type 2 (SCA2) is a subtype of type I autosomal dominant cerebellar ataxia (ADCA type I; see this term) characterized by truncal ataxia, dysarthria, slowed saccades and less commonly ophthalmoparesis and chorea. 